\title{
DESEMPENHO DAS COMPANHIAS PÓS-FUSÕES E AQUISIÇÕES MENSURADO PELOS FILTROS DE GRAHAM
}

\author{
PERFORMANCE OF POST-MERGERS AND ACQUISITIONS COMPANIES \\ MEASURED BY GRAHAM FILTERS
}

\author{
LEANDRO AUGUSTO TOIGO \\ Doutor em Ciências Contábeis e Administração pela FURB. Professor \\ Adjunto do Mestrado em Contabilidade da UNIOESTE. Endereço: \\ Rua Universitária, 2069, Sala 70 / Jardim Universitário / 85819-110, \\ Cascavel/PR / Brasil. \\ E-mail: leandro.toigo@unioeste.br
}

\begin{abstract}
NELSON HEIN
Doutor em Engenharia de Produção pela Universidade Federal de Santa Catarina (UFSC). Professor do Doutorado em Ciências Contábeis e Administração da Fundação Universidade Regional de Blumenau (FURB). Endereço: Rua Antônio da Veiga, 140, sala D202 I Victor Konder, Blumenau/SC / Brasil.

E-mail: hein@furb.br
\end{abstract}

\begin{abstract}
RESUMO
O estudo objetiva verificar o desempenho das companhias que realizaram fusões e aquisições por meio da avaliação de desempenho com o uso dos Filtros de Graham. A pesquisa, caracterizada como descritiva, documental e quantitativa, foi realizada a partir de dados contábeis, financeiros e de mercado de quarenta e duas companhias abertas brasileiras listadas na BM\&FBovespa, que realizaram fusões e aquisições com troca de controle entre os períodos de 2006 e 2010. Os dados sobre as fusões e aquisições foram coletados junto ao sítio da CVM - Comissão de Valores Mobiliários em fatos relevantes. As informações sobre o desempenho foram levantadas junto à base Economática ${ }^{\circledR}$. Calculou-se o desempenho das quarenta e duas companhias por sete Filtros de Graham, transformados em um ranking pela aplicação do TOPSIS. Pelos resultados, verifica-se que nos cinco anos de análise as companhias tiveram variações positivas de desempenho no ranking. Como contribuição ao cálculo de desempenho das empresas, os Filtros de Graham permitiram identificar a elevação do lucro líquido, redução do endividamento, aumento dos ativos. Com esses resultados constata-se que as companhias que passaram por fusões e aquisições apresentam boa saúde financeira e baixo risco. Como conclusão, tem-se que esses resultados do desempenho das companhias pelos Filtros de Graham nos processos de fusões e aquisições, realizados no ambiente brasileiro, apresentam razoável segurança aos acionistas e bom nível de Governança Corporativa.
\end{abstract}

Palavras-chave: Fusões e aquisições. Desempenho. Filtros de Graham.

\section{ABSTRACT}

The objective of this study was to verify the performance of the companies that performed mergers and acquisitions by evaluating performance with the use of Graham Filters. The 
research, characterized as descriptive, documentary and quantitative, was based on the accounting, financial and market data of 42 Brazilian companies listed on the BM\&FBovespa, which conducted mergers and acquisitions with exchange of control between 2006 and 2010. Data on mergers and acquisitions were collected from the CVM (Securities and Exchange Commission) website, and performance information was collected from the Economática® database. The performance of the 42 companies was calculated for the seven Graham Filters, and transformed into a ranking by the application of TOPSIS. From the results, it can be verified that in the five years of analysis the companies had positive variations of performance in the ranking. As a contribution to the company performance calculation, Graham Filters allowed us to identify the increase in net income, reduction of indebtedness and increase in assets. With these results, it can be seen that companies that have gone through mergers and acquisitions have good financial health and low risk. As a conclusion, these results of Graham Filters' performance in mergers and acquisitions, carried out in the Brazilian environment, show reasonable shareholder safety and a good level of Corporate Governance

Keywords: Mergers and acquisitions. Performance. Graham Filters.

\section{INTRODUÇÃO}

A literatura sugere vários motivos para conduzir as empresas a decisões de investimento. Um dos principais o crescimento da companhia. O processo de crescimento interno (por meio do próprio lucro) pode ser mais longo e custoso do que a compra do negócio já estabelecido (fusão e aquisição) (Singh \& Montgomery, 1987). A decisão de Fusão e aquisições, segundo Gitman (1997), objetiva predominantemente maximizar a riqueza dos proprietários, o que será refletido no preço da ação da companhia adquirente.

No ambiente empresarial brasileiro, as fusões e aquisições também passaram a ocorrer com maior intensidade, principalmente a partir da década de 1980 e 1990, que foram marcadas pela redução das restrições ao comércio internacional, pelo programa de privatizações do governo, pela liberalização financeira e pela ausência de uma lei antitruste rígida no Brasil (Marion \& Vieira, 2010).

As decisões de investimentos em fusões e aquisições podem ser utilizadas pelo gestor para benefício próprio e contrário aos interesses dos acionistas, induzindo-os a aplicar recursos em negócios destinados ao fracasso. Essas operações de aquisições de ativos (fusões e aquisições) geram dependência da empresa em relação a sua gerência (Shleifer \& Vishny, 1989). Dessa forma, o gestor percebe o campo fértil para suas deliberações, que nem sempre atendem aos interesses dos investidores.

Para avaliar esse conflito de interesses, surgiram pesquisas sobre fusões e aquisições e os retornos anormais, que, por sua vez, têm se concentrado principalmente na criação de valor à companhia, avaliada pelos retornos anormais das ações. Diante desse cenário, não foi observado pelas pesquisas expostas alguma forma específica que avaliasse criteriosamente tais retornos superiores dos mercados utilizando análise de valor (valuation). Essa análise de valor é o tema de interesse da Análise Fundamentalista, na medida em que busca identificar empresas com bons fundamentos contábeis e financeiros.

Entre as formas de se fazer essa análise, chama a atenção a abordagem dos criadores do valuation, Benjamin Graham e David Dodd em 1934, os quais desenvolveram um modelo matemático-estatístico que avalia composto por 10 filtros, que consideram indicadores do mercado de ações e econômico-financeiros das companhias (Graham, 2007). O objetivo principal dos 10 filtros de Graham é identificar empresas com bons índices do mercado de capitais, boa saúde financeira e estabilidade de lucro, que apresentem bons rendimentos de longo prazo (Oppenheimer, 1984; Zargham \& Hu, 1996; Damodaran, 2006). Lowe (1997, p. 100) afirma que "uma companhia que possua 7 dos 10 critérios pode ser considerada como avaliada com adequada margem de segurança".

No Brasil, são poucas as aplicações da metodologia. Em uma pesquisa recente, de 1994 a 2016, encontraram-se três estudos. Passos (2006) discutiu a teoria de Graham e aplicou-a ao mercado de capitais brasileiro, com base em dados de 1994 a 2000. Construiu um 
portfólio e avaliou os cinco anos seguintes. O retorno das ações da carteira que passou por todos os Filtros de Graham foi de $566 \%$, contra $219 \%$ do lbovespa. Porém, não mencionou a realização de testes estatísticos de significância.

Artuso e Chaves (2010) buscaram avançar no entendimento do mercado de ações do Brasil e na análise de estratégias eficazes para o pequeno investidor. Para isso, propuseram a aplicação dos Filtros de Graham para a definição de ativos na BM\&FBovespa no período de 1998 a 2009. Com análise dos resultados em quartil para cada filtro identificaram investimentos com retornos superiores à média de retorno do índice lbovespa para todos os períodos analisados.

Por último e mais recentemente, Artuso (2012) realizou um estudo no período de 1999 a 2009 com base na Hipótese do Mercado Eficiente (HME). Encontrou indícios contrários à eficiência do mercado doméstico. O retorno longitudinal da carteira selecionada foi de $39,78 \%$ contra $12,37 \%$ do Ibovespa. O diferencial do estudo de Artuso (2012) frente aos anteriores foi a realização de testes de significância estatística. Os resultados demonstraram sucesso na aplicação dos Filtros de Graham no reconhecimento de padrões. É possível explicar boa parte da variabilidade dos dados a partir dos fatores liquidez, precificação do valor contábil, rentabilidade e grau de endividamento.

No período pós-fusões e aquisições não se encontrou estudos no Brasil que mensurassem o desempenho das companhias pelos Filtros de Graham. Tais filtros representam um método matemático composto por 10 filtros, que são de mercado ou bursátil, financeiros e econômicos das empresas. Diante do exposto, surge a pergunta de pesquisa: Qual é o desempenho das companhias que passaram por fusões e aquisições mensurado pelos Filtros de Graham? Decorrente da questão de pesquisa, o estudo objetiva verificar o desempenho das companhias que passaram por fusões e aquisições por meio da mensuração dos Filtros de Graham.

Um dos fatores que justifica o estudo é o quadro de mudanças proporcionado pelo aumento de fusões e aquisições no mercado de capitais brasileiro nos últimos 20 anos, que eram de 176 operações em 1993 e passaram para 796 operações anuais em 2013 (KPMG, 2013). Tais operações consistem em simples aquisições de ações, acima de $10 \%$, fusões e incorporações com ou sem troca de controle acionário. Essas alterações econômicas provocadas pelo representativo volume de operações de fusões e aquisições, aliadas aos escândalos financeiros de 2001 e à crise sub-prime de 2008, tem exigido um ambiente corporativo e gerencial mais sólido dos mercados de capitais emergentes, inclusive o brasileiro. Assim, a transparência das ações dos executivos e a busca pela maximização da riqueza do proprietário com o maior desempenho da companhia passam a ser um dos princípios norteadores das ações dos executivos nas organizações.

Outro fator que justifica a presente pesquisa é sua amplitude e profundidade, quando comparada com as demais pesquisas realizadas no mercado de capitais brasileiro. As pesquisas existentes não realizaram um recorte temporal de cinco anos como foi realizado por este estudo, observando-se o período pós-fusões e aquisições em quatro anos, como análise de sensibilidade. Adicionalmente, este estudo contempla o aperfeiçoamento de instrumentos para mensurar o desempenho das companhias, pois até então estudos internacionais e nacionais realizaram avaliação do desempenho com o retorno das ações. Como a proposta deste estudo é avaliar o desempenho das companhias com a aplicação dos Filtros de Graham, a avaliação está sendo feita com a aplicação de indicadores contábeis, financeiros e bursáteis, que, por sua vez, indicam padrões de mercado, saúde financeira e estabilidade de lucro das companhias após as fusões e aquisições. Dessa forma, é possível proporcionar uma análise criteriosa do desempenho das companhias que passaram por fusões e aquisições, disponibilizando ao investidor mais uma forma de avaliação além do simples retorno anormal das ações. 


\section{REFERENCIAL TEÓRICO}

\subsection{Fusões e aquisições}

O foco da pesquisa foi estudar as fusões, aquisições e incorporações com troca de controle acionário. Entretanto, Silva, Gallo, Pereira e Lima (2004) explicam que o significado de incorporação utilizado no Brasil difere do conceito norte-americano e do europeu, que consideram essa operação como um tipo especial de fusão. Devido à literatura internacional tratar sobre fusões e incorporações como sendo uma única reestruturação societária, abordase a seguir somente os conceitos sobre fusões e aquisições.

A transferência da propriedade e controle de uma empresa pode ocorrer de duas formas: a empresa é adquirida por um grupo de pessoas ou outra empresa; ou a empresa se funde com outra, ocorrendo a combinação de negócios. Ambas as situações serão denominadas de tomada de controle, ou melhor, takeover. Costuma-se denominar a empresa que assume o controle como empresa adquirente, acquirer ou ainda bidder, enquanto que a empresa vendida é chamada de empresa alvo, empresa adquirida ou ainda empresa target (Berk \& Demarzo, 2009).

As fusões e aquisições costumam ser classificadas quanto à forma de pagamento e à relação comercial entre a empresa adquirente e empresa alvo. Quanto à forma de pagamento, as fusões e aquisições podem ocorrer com pagamento em caixa, troca de ações (ações da empresa adquirente e empresa alvo) ou a combinação de ambas as formas (Berk \& Demarzo, 2009).

As operações de fusões e aquisições ainda não estão totalmente assimiladas e sedimentadas em uma teoria geral que Ihes sirva de suporte. Para Kloechner (1994), o que há é um conjunto de explicações que se propõe a conferir-lhe legitimidade, derivado de alguns aspectos das teorias da empresa. Referente à questão de eficiência e ganhos (sinergia), Weston (1994) apresenta cinco hipóteses diferentes que explicam a atividade de fusões e aquisições, conforme a Tabela 1.

Tabela 1

Hipóteses sobre a eficiência e os ganhos em fusões e aquisições

\begin{tabular}{l|l}
\hline \multicolumn{1}{c|}{ Hipóteses } & \multicolumn{1}{c}{ Argumentos teóricos } \\
\hline Eficiência & $\begin{array}{l}\text { Uma fusão e aquisição pode melhorar tanto o desempenho da empresa quanto produzir } \\
\text { uma empresa mais eficiente, devido à obtenção de algum tipo de sinergia. }\end{array}$ \\
\hline Informação & $\begin{array}{l}\text { Efeito de curto prazo causado por cotação de ações das companhias envolvidas no } \\
\text { mercado, que tentam incorporar ao preço o resultado ou o desdobramento da união. }\end{array}$ \\
\hline Agência & $\begin{array}{l}\text { As fusões e aquisições podem ser um mecanismo para minimizar os problemas e custos } \\
\text { de agência. }\end{array}$ \\
\hline Poder de mercado & $\begin{array}{l}\text { Se as economias esperadas pelas fusões e aquisições não ocorrerem, o aumento na } \\
\text { concentração foi motivado por ganho de monopólio. }\end{array}$ \\
\hline Impostos & Fusões e aquisições são motivadas por ganhos tributários. \\
\hline
\end{tabular}

Nota. Fonte: Weston, J. F. (1994). The payoff in mergers and acquisitions. In M. Rock, R. H. Rock \& M. Stroka (editors). The mergers and acquisitions handbook (2a ed.). New York: McGraw-Hill.

Além dessas hipóteses ou explicações para a atividade de fusões e aquisições, Kloechner (1994) e Camargo e Barbosa (2003) apresentam as hipótese da(os): maximização da riqueza; maximização da utilidade gerencial; ganhos operacionais (sinergia); informação nova; eficiência de mercado; eficiência de ganhos; diversificação.

As fusões e aquisições ocorrem quando a empresa adquirente acredita adicionar valor econômico por meio da aquisição, o que o investidor comum não seria capaz de realizar (Nardi, 2012). Berk e Damarzo (2009) descrevem que as fusões e aquisições geram incremento de valor que é resultante da sinergia criada pela combinação das duas empresas. É essa razão a mais usada para justificar o negócio realizado, mesmo havendo a necessidade do pagamento do prêmio adicional ao valor do mercado.

Para Berk e Damarzo (2009), a sinergia e sua consequente criação de valor é originária de duas fontes: a) aumento de receita gerada pela união das duas empresas fomenta a oportunidade de atuação em novos mercados, com novos produtos e ampliação do número de 
clientes e consumidores; b) sinergia gerada por meio da redução de custos, é usualmente obtida pela eliminação de áreas duplicadas e otimização dos recursos remanescentes.

\subsection{Desempenho das companhias}

O foco deste estudo não se refere à avaliação de desempenho empresarial medido simplesmente pelo retorno das ações para tomada de decisão, mas à avaliação de desempenho considerando, além do retorno das ações, a saúde financeira e a estabilidade de lucro das companhias, pontos contemplados pelos 7 Filtros de Graham.

Entende-se que diversos fatores influenciam os preços das ações, tanto internos, como os relacionados ao desempenho das empresas emissoras de ações, quanto externos, relacionados à economia do país. Para Mellagi e Ishikawa (2003, p. 274), "para dar conta dos inumeráveis fatores, é mais do que necessária a compreensão de métodos estatísticos para a avaliação do risco dos investimentos". Frente aos modelos de precificação, que, por sua vez, são essencialmente matemáticos e estatísticos, estende-se essa compreensão à medida que a avaliação de retorno só faz sentido se estimado com o risco envolvido no investimento. Dessa forma, para precificar um ativo ou precificar um retorno esperado sobre um investimento arriscado, conhecimentos estatísticos são necessários.

A seleção de ativos com base em uma série de filtros, que podem ser determinados por meio de múltiplos de mercado e outros indicadores econômico-financeiros, é conhecida como a filtragem passiva, idealizada por Graham e Dodd (1951). Os autores identificaram certas características nas empresas, como boa gestão, baixo risco e bons lucros, como determinante para que as ações dessas empresas tivessem desempenho acima do mercado e traduziram estas características qualitativas em critérios quantitativos, que podem ser utilizados para identificação de investimentos promissores.

A ideia do que realmente representa um investimento é singular para esses autores, que conceituam-no como "uma operação que, após análise profunda, promete a segurança do principal e um retorno adequado" (Graham \& Dodd, 1951, p. 43).

Artuso (2012) aborda que na primeira edição de Security Analisys de 1934, Dodd e Graham apresentaram os dez filtros para a identificação de ativos com retorno promissor. Nas edições posteriores os filtros sofreram pequenos ajustes. Em 2003, os Filtros de Graham voltaram à discussão com o lançamento do livro "The Intelligent Investor", de Benjamin Graham.

Para Artuso (2012), os Filtros de Graham realizam análise de valor (valuation). O tema é de interesse da análise fundamentalista, na medida em que busca identificar companhias com bons fundamentos contábeis/financeira e subavaliadas pelo mercado. Assim Benjamin Graham foi considerado o criador do valuation. Tais fundamentos compõem uma nova forma de avaliação que prima pela saúde financeira da empresa e menor risco do investimento realizado. Para esclarecer melhor a função desses dez filtros, cabe uma discussão com maior profundidade sobre cada um deles.

Filtro 1 (F1) - Um índice lucro/preço igual ao dobro do rendimento de um título de renda fixa classificado como AAA (baixo risco) (Graham \& Dodd, 1951). Esse filtro identifica a relação do lucro com o preço da ação e se tal relação ultrapassou o dobro do rendimento de um título AAA, praticamente livre de riscos. Seu objetivo é identificar ações das companhias que produzam rendimento maior que um título livre de risco. A classificação AAA é dada por agências como a Moody's e a Standard \& Poors, que avaliam riscos dos títulos. Neste estudo foi utilizada a taxa Selic média anual, que renumera os títulos públicos no Brasil, para os cinco anos da análise, ou seja, para um ano antes e quatro anos depois do evento pesquisado (fusões e aquisições). A taxa Selic no Brasíl é elevada; em 2010, que foi o último ano de análise do estudo, ficou em 10,03\%, enquanto nos Estados Unidos gira em torno de 0,25\%. Dessa forma, não é muito frequente as companhias apresentarem uma boa avaliação nesse filtro do Graham (Artuso, 2012).

Filtro 2 (F2) - Múltiplo Preço por Lucro, P/L, da ação menor que 40\% do P/L médio do mercado nos últimos cinco anos (Graham \& Dodd, 1951). Esse filtro também relaciona preço das ações e lucro como o filtro número 1, porém compara o resultado da mesma relação de títulos existentes no mercado nos últimos cinco anos. O filtro busca identificar ações com preço 
abaixo de $40 \%$ do lucro na média dos últimos cinco anos, assim tais ações podem estar subavaliadas (Artuso, 2012).

Filtro 3 (F3) - Taxa de dividendos maiores do que dois terços do rendimento de um título de renda fixa classificado como AAA (Graham \& Dodd, 1951). Além do retorno com a liquidez das ações, o investidor recebe dos dividendos - dividend yield - que é distribuído ao acionista em datas determinadas. Esse filtro busca identificar investimentos que remunerem por meio de dividendos dois terços do rendimento de um título livre de risco e classificado no nível AAA. Neste estudo foi utilizada a taxa Selic para representar tais títulos livres de risco (Artuso, 2012).

Filtro 4 (F4) - Preço inferior a dois terços do Valor Contábil Tangível, entendido como o Patrimônio Líquido menos o Ativo Intangível (Graham \& Dodd, 1951). Esse filtro faz uma relação do preço total das ações. Ele é inferior a dois terços do Valor Contábil Tangível da companhia. Esse filtro busca identificar ações subavaliadas, concedendo-lhes uma boa margem de segurança. Normalmente os pesquisadores utilizam o patrimônio líquido, mas Graham é mais conservador e retira os ativos intangíveis da análise, pois podem apresentar distorções elevadas. Dentro da lógica desse filtro, torna-se possível adquirir companhias a um valor que chega a 33\% do patrimônio líquido (Artuso, 2012). Para exemplificar, comenta-se um caso hipotético em que uma companhia tivesse alcançado o valor de mercado que corresponderia a $33 \%$ do seu patrimônio líquido. Isso quer dizer que, em caso de compra, o investidor pagaria $R \$ 0,33$ por cada $R \$ 1,00$ de patrimônio da empresa, representando assim um negócio interessante para ser adquirido.

Filtro 5 (F5) - Preço inferior a dois terços do Capital de Giro Líquido, compreendido como sendo Ativo Circulante menos a Dívida Total (Graham \& Dodd, 1951). Dívida total corresponde às dívidas de curto e longo prazos. Esse filtro relaciona o preço da ação com o capital de giro líquido. Pode ser considerado o mais restritivo de todos. É o critério mais poderoso para identificar se a companhia está sendo subavaliada, pois trata de comparar o preço de mercado com os ativos mais líquidos da empresa e transformáveis em moeda. Quando atendido o filtro, seria possível adquirir a empresa sem pagar pelos ativos imobilizados. Atender a esse filtro de Graham quando os mercados estão em alta parece algo raro, porém encontrar uma empresa nessas condições é uma relevante oportunidade (Artuso, 2012).

Filtro 6 (F6) - Dívida total menor que o Valor Contábil Tangível (Graham \& Dodd, 1951). Com esse filtro, analisa-se o risco financeiro da empresa, correspondente a um índice de endividamento, que indica a estrutura de capital da empresa. O filtro busca avaliar a capacidade da empresa em aumentar o seu valor contábil tangível e diminuir a dívida total, ou seja, o filtro avalia a força financeira da empresa produzindo mais recursos financeiros do que sua necessidade de financiamento (Artuso, 2012). Graham (2007) descreve que um negócio representativo gera mais dinheiro do que consome, e bons administradores usam o dinheiro de forma produtiva. No longo prazo, as empresas que mantiverem esse padrão terão seu valor de mercado ampliado, independentemente do crescimento das demais companhias.

Filtro 7 (F7) - Ativo Circulante mais de duas vezes maior que o Passivo Circulante (Graham \& Dodd, 1951). Esse filtro corresponde ao índice de liquidez corrente. Buscam-se empresas que apresentem liquidez corrente maior que 1. Representa que as empresas possuem recursos para saldar suas dívidas a curto prazo. Esse critério é conservador para Graham, que estabelece um índice ideal maior que 2 (Artuso, 2012). O autor relata que em 2010 a liquidez corrente média das companhias abertas alcançou o patamar de 1,45\%.

Filtro 8 (F8) - Dívida total menor que duas vezes o Capital de Giro Líquido (Graham \& Dodd, 1951). Esse filtro identifica o índice de liquidez modificado. Uma empresa financiada conservadoramente teria à sua disposição em caixa, pelo menos, a metade do valor de suas dívidas, o que the concederia um valor muito baixo de inadimplência (Artuso, 2012).

Filtro 9 (F9) - Crescimento do lucro por ação maior do que $7 \%$ durante os últimos 10 anos (Graham \& Dodd, 1951). Para Graham (2007), se os lucros das ações crescerem de forma estável, pelo menos $6 \%$ ou $7 \%$ nos últimos dez anos, a companhia é geradora de dinheiro estável e suas perspectivas de crescimento são boas. O maior problema da empresa negociada são os múltiplos de mercado, alvo dos 5 primeiros filtros e que possuem baixo crescimento (Artuso, 2012). 
Filtro 10 (F10) - Não mais do que dois anos de lucros em declínio de $5 \%$ ou mais nos últimos 10 anos (Graham \& Dodd, 1951). Esse último filtro busca identificar a estabilidade do lucro, de forma que o objetivo é que somente as empresas que apresentam pequenas variações nos seus lucros, indicando um crescimento sustentável, façam parte da carteira do investidor (Artuso, 2012).

Após a obra seminal de Graham e Dodd (1951) surgiram outros pesquisadores disseminando e utilizando os princípios dos Filtros de Graham. Lander, Orphanides e Douvogiannis (1997) formalizaram a observação de Graham e Dodd, de que as avaliações de ações e títulos estão ligadas por uma relação de equilíbrio entre os rendimentos dos dividendos previstos e os rendimentos reais dos títulos. Que os preços das ações tendem a se mover para restaurar desvios a partir desse equilíbrio. Com o modelo econométrico os pesquisadores obtiveram previsões com um mês de antecedência.

Bildersee, Chen e Zutshi (1993) relataram que a estratégia de investimento de Benjamin Graham parecia estar funcionando no mercado de ações japonês. Os autores em seu estudo encontraram resultados que indicam que o retorno das carteiras elaboradas com base nos Filtros de Graham é positivo e tende a superar o retorno de outras carteiras que não aplicam os referidos filtros no mercado de ações japonês.

Arnott, Hsu e Moore (2005) examinaram uma série de índices ponderados do mercado de ações por métricas fundamentais, em vez de capitalização de mercado. Eles concluíram que esses índices proporcionaram benefícios consistentes e significativos em relação aos índices de mercado padrão. Eles mostram retornos anuais que são, em média, 213 pontos acima dos índices de capitalização ponderada equivalentes ao longo dos 42 anos do estudo.

Bogle (2008) comenta que os princípios de investimento simples defendidos desde 1951 por Benjamin Graham permanecem válidos até 2008. Estratégias de investimentos tornaram-se muito mais ativas. O setor financeiro tem vindo a desempenhar um papel dominante na economia mundial. Em outro artigo, Bogle (2009) traça as causas da crise financeira de 2009, indicando mudanças de valores éticos, citando uma lista de violações dos deveres fiduciários por gestores de fundos mútuos. Com base na sabedoria de Harlan Fiske Stone, Benjamin Graham e John Maynard Keynes, Bogle defende uma lei federal de deveres fiduciários para os gestores institucionais.

Calandro (2009) estudou como os altos executivos em uma variedade de setores econômicos podem encontrar lições importantes na sexta edição recentemente publicada de Graham e Dodd (2008). Esse documento inclui uma entrevista com o editor principal do livro, investidor em valor Seth Klarman, que explica lições estratégicas-chave que os executivos não financeiros podem aprender com os conceitos de valor de investimento e metodologia.

Cheung (2010) relatou que Benjamin Graham, o pai do investimento em valor, argumentou que o mercado de ações sofre de um transtorno de humor conhecido como transtorno bipolar. Warren Buffet e John Maynard Keynes também endossaram a ideia de que a psicologia do mercado tem um papel influente a jogar no mercado de ações. A explicação do autor utiliza três bolhas de mercado como ilustração: 1990 bolha japonesa; 2000 bolha da Internet e 2007 crise das hipotecas subprime.

Woods (2013) relatou em seu estudo que um economista britânico chamado John Keynes teria admitido, em 1938, que a sua abordagem à gestão de carteiras de investimentos em ações em curso teria mudado dramaticamente. Keynes teria abandonado o perfil de especulador em favor de um perfil de investidor, ou seja, uma cuidadosa seleção de alguns investimentos tendo em conta o seu baixo preço e potencial de valor intrínseco em ano anterior à aquisição das ações, assim ele estava aplicando os Filtros de Benjamin Graham.

Artuso e Chaves (2010) buscaram compreender o mercado de ações brasileiro e analisaram estratégias para o pequeno investidor. Propuseram a aplicação dos Filtros de Graham para a seleção de companhias para comprar ações no período de 1998 a 2009. A carteira indicada pelos Filtros de Graham produziu retornos anormais superiores ao Ibovesta, entretanto, a carteira apresentava baixa diversificação.

Kreuzberg, Beck, Gollo, \& Rosa (2014) avaliaram uma carteira de investimentos das companhias listadas nos níveis de governança corporativa da BM\&FBovespa, por meio da aplicação dos Filtros de Graham, em consonância ao contexto brasileiro. Em seguida, aplicaram a análise dos componentes principais, buscando reduzir a dimensão das variáveis. 
Os resultados indicaram que o critério da estabilidade nos lucros apresentou o menor número de empresas adaptadas, seguido pelo sexto critério. Por outro lado, os critérios 1 e 7 evidenciaram o maior índice de adequação. Verificaram que apenas 22 empresas se apresentaram em conformidade com todos os sete critérios analisados pelos Filtros de Graham.

Ferreira e Santos (2014) compararam a eficiência em desempenho de uma carteira gerada pela aplicação dos Filtros de Graham (carteira A) e outra originada do emprego dos preceitos do modelo de Elton-Gruber (carteira $B$ ), tendo como escopo ações ordinárias listadas na BM\&FBovespa, no período que vai de 2008 a 2012. A Carteira B apresentou um retorno maior, porém, um risco mais alto que a Carteira A. A Carteira B seria um investimento mais adequado a um investidor de perfil mais agressivo, enquanto que a Carteira A serviria melhor às expectativas de um investidor conservador.

Zin e Tarso (2016) verificaram a eficiência dos Filtros de Graham e o modelo da fronteira eficiente de Harry Markowitz, para definir a participação de cada ativo na composição das carteiras. O período estudado compreende os anos de 2006 a 2010, ou seja, dois anos anteriores e dois anos posteriores à crise mundial de 2008. Os resultados mostraram que é possível minimizar os riscos e obter retornos superiores ao índice lbovespa, compondo carteiras com pequeno número de ativos.

Artuso (2012) objetivou compreender o mercado de capitais brasileiro, propondo e analisando estratégias de seleção de carteira. Os melhores resultados foram alcançados pelo modelo de filtragem construído a partir dos Filtros de Graham, em que o retorno anual foi de $39,78 \%$, em face de $12,37 \%$ do Ibovespa. Assim, as técnicas empregadas permitiram uma maior compreensão do mercado acionário e indicaram a possibilidade de se identificar sistematicamente ativos subavaliados, e de se obter retornos excedentes.

Passos (2006) explica que a análise fundamentalista tem sido forte aliada do mercado de capitais e tem em Benjamin Graham um de seus principais expoentes. O autor aplicou os conceitos de Graham, adaptando-os à realidade brasileira e considera a pesquisa realizada um avanço no aprendizado de variáveis que se correlacionam com o mercado bursátil, contribuindo para futuros investidores.

Em resumo, os Filtros de Graham foram idealizados por Benjamin Graham e David Dodd no livro Security Analisys de 1934 (primeira edição). Depois houve a publicação do livro The Investor Intelligent em 2003 e, na sequência, é considerável o número de publicações de artigos. Com esses fatos, percebe-se que depois de 2005 intensificaram-se as discussões sobre os Filtros de Graham. Isso pode estar atrelado à maior preocupação do investidor com os seus investimentos e os filtros poderiam estar atendendo às suas necessidades de avaliação.

\section{ASPECTOS METODOLÓGICOS}

$O$ delineamento de pesquisa consiste no seu planejamento e relaciona-se à metodologia adotada, considerados o ambiente em que os dados são coletados e as formas de controle das variáveis envolvidas (Gil, 2006). Para Kerlinger (1980), o delineamento de um estudo relaciona-se ao modo pelo qual o problema de pesquisa é concebido e à estrutura utilizada para a experimentação, a coleta e análise dos dados.

Hair, Babin, Money, \& Samouel (2005, p. 86) descrevem que "os planos de pesquisa descritiva em geral são estruturados e especificamente criados para medir as características descritas em uma questão de pesquisa". Quanto à pesquisa documental, Gray (2012) relata que o uso de documentos consiste em uma das formas não invasivas mais utilizadas, pois podem ser utilizados documentos que trazem registros financeiros, políticos e jurídicos de organizações ou instituições. Inseridos nesse contexto, as características deste estudo permitem classificá-lo como pesquisa descritiva com abordagem quantitativa, realizada por meio de pesquisa documental.

Martins e Theóphilo (2009) reconhecem como principal característica a tipologia das fontes de dados, informações e evidências que são exclusivas dos documentos de fontes primárias, materiais compilados pelos pesquisadores, que ainda não foram objeto de análise, ou trabalhados de acordo com os objetivos da pesquisa. Nesta pesquisa, a coleta foi do tipo 
documental, a partir dos dados contábeis, financeiros, de mercado, disponíveis na base de dados Economática ${ }^{\circledR}$ e dados societários publicados nos sítios da BM\&FBovespa S.A. e CVM Comissão de Valores Mobiliários, divulgados pelas companhias investigadas, os quais evidenciam características de fontes secundárias, já que não receberam tratamento analítico.

A composição da população de pesquisa foi definida considerando-se as companhias de capital aberto listadas na BM\&FBovespa S.A. A escolha pelas companhias de capital aberto deu-se pelo fato delas terem suas informações contábeis, financeiras, de mercado e societárias amplamente divulgadas. Com a definição da população, realizou-se consulta por data junto ao sítio da Comissão de Valores Mobiliários (CVM) em "Fatos relevantes" e teve-se acesso a todos os comunicados importantes que as companhias divulgam aos seus acionistas. Buscando apenas comunicados sobre fusões, incorporações e aquisições chegou-se à amostra final de quarenta e duas companhias, conforme a Tabela 2.

Tabela 2

Composição da amostra

\begin{tabular}{c|c|c|c|c}
\hline Ano & $\begin{array}{c}\text { Empresas } \\
\text { listadas }\end{array}$ & $\begin{array}{c}\text { (-) Empresas financeiras e } \\
\text { seguradoras }\end{array}$ & (=) População & $\begin{array}{c}\text { (=) Número de fusões e } \\
\text { aquisições }\end{array}$ \\
\hline 2006 & 394 & $(90)$ & 304 & 2 \\
\hline 2007 & 449 & $(96)$ & 353 & 7 \\
\hline 2008 & 439 & $(111)$ & 328 & 11 \\
\hline 2009 & 434 & $(115)$ & 319 & 9 \\
\hline 2010 & 471 & $(114)$ & 357 & $\mathbf{4 2}$ \\
\hline Total & $\mathbf{2 . 1 8 7}$ & $\mathbf{( 5 2 6 )}$ & $\mathbf{1 . 6 6 1}$ & 7 \\
\hline
\end{tabular}

Nota. Fonte: Dados da pesquisa.

Com base nos comunicados divulgados pela CVM, construiu-se a amostra intencional obedecendo a alguns critérios, segundo Wang e Xie (2009), tais como: a) negócios firmados entre 2006 e 2010; b) fusões, incorporações e aquisições com troca do controle acionário; c) operações com valor acima de 1 milhão de dólares e 1\% do valor de mercado; d) em situações que a empresa adquirente realizava várias aquisições, considerou-se apenas aquela de maior valor. Como resultado da aplicação desses critérios constituiu-se a amostra final, que busca representar com maior fidedignidade possível todas as transformações societárias e estruturais pelas quais as empresas que realizam fusões e aquisições passam, assim melhor atendendo aos objetivos do estudo. $\mathrm{Na}$ Tabela 2, observa-se o número de empresas listadas na BM\&FBovespa entre 2006 e 2010. Extraíram-se as instituições financeiras e seguradoras devido a peculiaridades do SFN - Sistema Financeiro Nacional.

O ano limite para realizar a análise das fusões e aquisições foi 2010 , devido à avaliação pós-evento de quatro anos de desempenho das companhias. Assim, o evento que aconteceu em 2010 teve sua análise pós-fusões e aquisições realizada nos anos de 2011, 2012, 2013 e 2014. Dessa forma, caracteriza-se como um período de análise recente dentro das disponibilidades dos dados divulgados pelas companhias. Estabeleceu-se esse recorte recente por estar dentro do recorte de crescimento das fusões e aquisições indicada pela KPMG (2013).

Após a identificação das fusões e aquisições, realizou-se a etapa do cálculo do desempenho utilizando os Filtros de Graham. Para isso, iniciou-se a coleta de dados junto à Economática ${ }^{\circledR}$. Extraíram-se dados econômicos, financeiros e bursáteis das quarenta e duas companhias para a construção dos sete Filtros de Graham. Para cada empresa, coletaram-se informações de um ano antes e quatro anos depois das fusões e aquisições, totalizando cinco anos de informações para o cálculo de 1.470 operações.

A segunda etapa da preparação dos dados de desempenho das companhias foi a elaboração do ranking agregado dos resultados obtidos sobre os sete índices resultantes da aplicação dos Filtros de Graham. Para computar a medida agregada, aplicou-se o método de análise multicritério, conhecido como Technique for Order Preference by Smilarity to Ideal Solution (TOPSIS), desenvolvido por Hwang e Yoon (1981). A técnica TOPSIS é fundamentada no ranking de alternativas para obter a melhor seleção entre elas, a qual está mais próxima da solução ideal, levando em consideração a distância da solução ideal e da solução anti-ideal (Bulgurcu, 2012). Segundo essa técnica, a melhor alternativa deveria ser aquela que está mais 
próxima da solução ideal e o mais distante da solução ideal negativa (Benitez, Martin, \& Roman, 2007). Para o cálculo do método TOPSIS, aplicou-se adicionalmente o conceito do coeficiente de variância.

\section{APRESENTAÇÃO E ANÁLISE DOS RESULTADOS}

Nesta seção discorre-se sobre os procedimentos matemáticos e estatísticos adotados para o cálculo do desempenho das companhias que utilizou sete Filtros de Graham e, que foram transformados em ranking pelo TOPSIS. Para isso, coletaram-se os dados econômicos, financeiros e bursáteis da base de dados Economática ${ }^{\circledR}$ das quarenta e duas companhias da amostra.

Logo em seguida, sobre os dados coletados, foi aplicada a fórmula matemática dos Filtros: F1, F3, F4, F5, F6, F7 e F8. Os filtros F2, F9 e F10 não foram aplicados neste estudo, pois necessitariam de dados médios de 5 a 10 anos posteriores ao ano de 2010, que, por sua vez, não estavam disponíveis até o momento da coleta realizada. Artuso e Chaves (2010) descrevem que os cinco primeiros filtros referem-se aos múltiplos de mercado e os filtros 6 a 8 são relativos à saúde financeira. Diferente da pesquisa de Artuso (2012), que considerou apenas quem atendeu $100 \%$ dos Filtros de Graham, este estudo levou em conta os níveis de atingimento dos filtros e fez um ranking das empresas por meio do TOPSIS. Aplicaram-se os sete Filtros de Graham nas quarenta e duas companhias em cinco anos, ou seja, um ano antes do evento $(t-1)$ e quatro anos depois $(t+1)$, $(t+2)$, $(t+3)$ e $(t+4)$. Encontraram-se sete índices dos filtros por ano, em cinco anos, referentes a quarenta e duas companhias que totalizaram 1.470 resultados dos Filtros de Graham. Utilizou-se o TOPSIS para agrupar os sete índices dos anos e proporcionar a empresa uma posição no ranking.

O método TOPSIS é uma técnica para avaliar o desempenho das alternativas por intermédio da similaridade com a solução ideal (Hwang \& Yoon, 1981). Segundo o mesmo autor, de acordo com essa técnica, a melhor alternativa seria aquela que está mais próxima da solução ideal, composta de todos os melhores valores atingíveis dos critérios de benefícios. Entretanto, a solução ideal negativa consiste em todos os piores valores atingíveis dos critérios do objetivo proposto neste estudo.

Ademais, como procedimento complementar, foi aplicado junto ao TOPSIS a técnica do coeficiente de variação, que identificou os resultados dos filtros que tiveram maior variação, dando-lhes maior peso na fórmula, conforme apresentado na Tabela 3. O coeficiente de variação é utilizado para identificar os filtros de maior relevância para as companhias e considerá-los no ranking TOPSIS.

Tabela 3

Peso dos Filtros de Graham

\begin{tabular}{l|r|r|r|r|r|r|r}
\hline & F1 & F3 & F4 & F5 & F6 & F7 & \multicolumn{1}{c}{ F8 } \\
\hline $\mathrm{T}-1$ & $6,03 \%$ & $4,87 \%$ & $4,21 \%$ & $71,71 \%$ & $3,29 \%$ & $2,03 \%$ & $7,87 \%$ \\
\hline $\mathrm{T}+1$ & $30,80 \%$ & $2,15 \%$ & $1,90 \%$ & $16,04 \%$ & $1,45 \%$ & $0,75 \%$ & $46,90 \%$ \\
\hline $\mathrm{T}+2$ & $3,85 \%$ & $0,84 \%$ & $0,93 \%$ & $2,90 \%$ & $0,70 \%$ & $0,39 \%$ & $90,39 \%$ \\
\hline $\mathrm{T}+3$ & $86,06 \%$ & $1,38 \%$ & $0,98 \%$ & $3,36 \%$ & $1,06 \%$ & $0,52 \%$ & $6,64 \%$ \\
\hline $\mathrm{T}+4$ & $32,69 \%$ & $9,37 \%$ & $10,43 \%$ & $17,25 \%$ & $6,71 \%$ & $2,66 \%$ & $20,89 \%$ \\
\hline
\end{tabular}

Nota. Fonte: Dados da pesquisa.

Com base na Tabela 3, verifica-se no período pré-fusões e aquisições $(\mathrm{t}-1)$ que o filtro cinco (F5) concentrou o maior peso, $71,71 \%$ do índice de ranking TOPSIS. No período pósfusões e aquisições, especificamente um ano depois $(t+1)$, tem-se o filtro um (F1) com $30,80 \%$ e o filtro oito (F8) com $46,90 \%$, compartilhando os maiores pesos do ranking gerado. Dois anos depois ( $t+2$ ), o filtro oito (F8) apresentou o peso surpreendente de $90,39 \%$. No terceiro ano após a fusão e aquisição, o filtro um (F1) apresentou maior peso com $86,06 \%$. Por fim, no quarto ano os pesos ficaram mais distribuídos. Entretanto, verifica-se que os filtros um (F1) e oito (F8) tiveram maiores pesos, o filtro um com $32,69 \%$ e o filtro oito com $20,89 \%$. Essas diferenças ocorrem porque os filtros que produziram maior peso tiveram maior variação 
dos dados utilizados. Assim, quanto maior for a diferença de resultados de um determinado filtro, maior é o seu peso pelo coeficiente de variação.

Após aplicação do TOPSIS com o coeficiente de variação sobre os sete Filtros de Graham, obteve-se o ranking do desempenho das empresas, conforme Tabela 4. Essa análise permite identificar as companhias que melhor atenderam aos sete Filtros de Graham simultaneamente, gerando uma forma inovadora de avaliação de desempenho pós-fusões e aquisições. Gerou-se cinco rankings, um para o período pré-fusões e aquisições e quatro para o período pós-fusões e aquisições.

\section{Tabela 4}

\section{Ranking de desempenho das companhias}

\begin{tabular}{|c|c|c|c|c|c|c|c|c|c|c|}
\hline NOMES & $t-1$ & RT & $t+1$ & RT & $t+2$ & RT & $t+3$ & RT & $t+4$ & RT \\
\hline ANDRADE GUTIERREZ CONCESSOES S.A. & 0,312 & 29 & 0,519 & 31 & 0,352 & 35 & 0,808 & 33 & 0,857 & 24 \\
\hline ALL AMERICA LATINA LOGISTICA S.A. & 0,396 & 15 & 0,530 & 28 & 0,391 & 26 & 0,806 & 34 & 0,855 & 29 \\
\hline ARTERIS S.A. & 0,291 & 36 & 0,460 & 39 & 0,261 & 42 & 0,818 & 29 &, 831 & 39 \\
\hline BRASKEM S.A. & 0,211 & 41 & 0,466 & 38 & 0,364 & 33 & 0,822 & 27 & 0,855 & 28 \\
\hline BRF S.A. & 0,385 & 17 & 0,597 & 13 & 0,553 & 11 & 0,823 & 26 & 0,861 & 21 \\
\hline BROOKFIELD INCORPORAÇÕES S.A. & 0,591 & 3 & 0,695 & 3 & 0,663 & 6 & 0,881 & 4 & 0,852 & 31 \\
\hline CCR S.A. & 0,194 & 42 & 0,506 & 35 & 0,328 & 40 & 0,826 & 23 & 0,854 & 30 \\
\hline CIA ENERG. DE MINAS GERAIS - CEMIG & 0,473 & 8 & 0,484 & 36 & 0,339 & 37 & 0,915 & 1 & 0,880 & 3 \\
\hline COSAN S.A. INDUSTRIA E COMERCIO & 0,324 & 25 & 0,537 & 25 & 0,392 & 25 & 0,907 & 2 & 0,859 & 22 \\
\hline CPFL ENERGIA S.A. & 0,270 & 38 & 0,516 & 32 & 0,370 & 30 & 0,840 & 16 & 0,856 & 26 \\
\hline DIAGNOSTICOS DA AMERICA S.A. & 0,342 & 23 & 0,555 & 22 & 0,437 & 22 & 0,825 & 24 & 0,858 & 23 \\
\hline DURATEX S.A. & 0,250 & 40 & 0,581 & 14 & 0,474 & 18 & 0,845 & 13 & 0,865 & 12 \\
\hline ECORODOVIAS INFRAEST. E LOGÍST. S.A. & 0,298 & 34 & 0,538 & 24 & 0,351 & 36 & 0,833 & 20 & 0,868 & 10 \\
\hline FIBRIA CELULOSE S.A. & 0,303 & 32 & 0,529 & 29 & 0,329 & 39 & 0,766 & 38 & 0,851 & 32 \\
\hline FLEURY S.A. & 0,594 & 2 & 0,603 & 11 & 515 & 13 & 0,829 & 22 &, 871 & 6 \\
\hline GAFISA S.A. & 0,595 & 1 & 0,841 & 1 & 0,619 & 7 & 0,864 & 9 & 0,843 & 37 \\
\hline GENERAL SHOPPING BRASIL S.A. & 0,305 & 30 & 0,562 & 18 & 0,475 & 17 & 0,800 & 36 &, 848 & 34 \\
\hline METALURGICA GERDAU S.A. & 0,337 & 24 & 0,555 & 21 & 0,421 & 24 & 0,861 & 11 & 0,864 & 13 \\
\hline GOL LINHAS AEREAS INTELIGENTES S.A. & 0,483 & 7 & 0,422 & 40 & 606 & 8 & 0,823 & 25 & 840 & 38 \\
\hline HYPERMARCAS S.A. & 0,350 & 21 & 0,641 & 6 & 0,581 & 10 & 0,804 & 35 & 0,856 & 27 \\
\hline INVEST. PART. EM INFRA S.A.-INVEPAR & 0,387 & 16 & 0,508 & 34 & 0,330 & 38 & 0,789 & 37 & 0,843 & 36 \\
\hline JBS S.A. & 0,416 & 12 & 0,528 & 30 & 0,445 & 20 & 0,832 & 21 & 857 & 25 \\
\hline LIGHT S.A. & 0,415 & 13 & 0,531 & 27 & 0,360 & 34 & 0,874 & 7 & 0,863 & 14 \\
\hline LUPATECH S.A. & 0,298 & 33 & 0,484 & 37 & 0,380 & 29 & 0,203 & 41 & 0,027 & 42 \\
\hline MARFRIG GLOBAL FOODS S.A. & 0,342 & 22 & 0,556 & 20 & 0,368 & 31 & 0,753 & 39 & 0,817 & 41 \\
\hline OI S.A. & 0,353 & 20 & 0,546 & 23 & 0,711 & 3 & 0,881 & 5 & 0,921 & 1 \\
\hline CIA BRASILEIRA DE DISTRIBUICAO & 0,464 & 9 & 0,636 & 7 & 0,594 & 9 & 0,839 & 17 & 0,863 & 16 \\
\hline PDG REALTY S.A. EMPREEND E PARTIC. & 0,421 & 10 & 0,778 & 2 & 0,803 & 1 & 0,862 & 10 & 0,873 & 5 \\
\hline PETROLEO BRASILEIRO S.A. PETROBRAS & 0,513 & 5 & 0,600 & 12 & 0,423 & 23 & 0,877 & 6 & 0,866 & 11 \\
\hline RENAR MACAS S.A. & 0,312 & 28 & 0,398 & 41 & 0,306 & 41 & 0,082 & 42 & 0,862 & 20 \\
\hline SANTOS BRASIL PARTICIPACOES S.A. & 0,305 & 31 & 0,572 & 16 & 0,388 & 27 & 0,821 & 28 & 0,863 & 17 \\
\hline SCHULZ S.A. & 0,278 & 37 & 0,604 & 10 & 0,504 & 16 & 0,868 & 8 & 0,871 & 7 \\
\hline CIA SIDERURGICA NACIONAL & 0,269 & 39 & 0,644 & 5 & 0,453 & 19 & 0,845 & 14 & 0,870 & 8 \\
\hline TRANS. ALIANÇA ENERGIA ELÉTRICA S.A. & 0,318 & 27 & 0,561 & 19 & 0,437 & 21 & 0,890 & 3 & 0,879 & 4 \\
\hline TRACTEBEL ENERGIA S.A. & 0,320 & 26 & 0,531 & 26 & 0,380 & 28 & 0,837 & 19 & 0,862 & 18 \\
\hline CTEEP - CIA TRANS. ELÉTR. PAULISTA & 0,418 & 11 & 0,570 & 17 & 0,505 & 15 & 0,855 & 12 & 0,884 & 2 \\
\hline TPI - TRIUNFO PARTICIP. E INVEST. S.A. & 0,296 & 35 & 0,165 & 42 & 0,367 & 32 & 0,810 & 31 & 0,850 & 33 \\
\hline ULTRAPAR PARTICIPACOES S.A. & 0,358 & 19 & 0,579 & 15 & 0,513 & 14 & 0,810 & 32 & 0,863 & 15 \\
\hline VANGUARDA AGRO S.A. & 0,491 & 6 & 0,514 & 33 & 0,667 & 4 & 0,686 & 40 & 0,847 & 35 \\
\hline VIA VAREJO S.A. & 0,398 & 14 & 0,620 & 9 & 0,667 & 5 & 0,811 & 30 & 0,862 & 19 \\
\hline VULCABRAS/AZALEIA S.A. & 0,372 & 18 & 0,631 & 8 & 0,553 & 12 & 0,844 & 15 & 0,826 & 40 \\
\hline WEG S.A. & 0,563 & 4 & 0,681 & 4 & 0,735 & 2 & 0,839 & 18 & 0,868 & 9 \\
\hline Média & 0,372 & & 0,556 & & 0,469 & & 0,800 & & 0,839 & \\
\hline
\end{tabular}

Nota. Fonte: Dados da pesquisa.

Legenda: RT - Ranking TOPSIS 
Os Filtros de Graham foram uma escolha para realizar a avaliação do desempenho considerando dados econômicos, financeiros e bursáteis. Este estudo não avaliou se a empresa passava ou não pelo filtro, conforme a pesquisa de Artuso (2012), mas, sim, o percentual de atingimento, ou seja, quanto mais próximo de $100 \%$, melhor.

O ranking dos sete Filtros de Graham pelo TOPSIS contribuiu significativamente para mensurar o desempenho das corporações em meio à crise Subprime que aconteceu em 2007, por ter relacionado os indicadores de desempenho da empresa com os de outras empresas. Isso talvez tenha contribuído para a realização de uma avaliação de desempenho isenta frente aos reflexos da crise.

A aplicação do TOPSIS contribuiu por ter transformado os resultados dos sete Filtros de Graham em um único indicador, o ranking, exposto na Tabela 4. Por meio do TOPSIS, é possível verificar qual companhia se encontra no topo do ranking ou em posição mais baixa. Quanto maior for a posição no ranking, melhor o nível de atingimento do conjunto dos sete Filtros do Graham em relação às demais empresas do grupo da amostra.

Pela Tabela 4, verifica-se que o desempenho das empresas pelos Filtros de Graham teve crescimento ao longo da análise pré e pós-fusões e aquisições. Isso foi constatado com base na média do período $(t-1)$ que foi de $(0,372)$, em comparação com os períodos pósfusões e aquisições. São eles: período $(t+1) \operatorname{com}(0,556)$; período $(t+2) \operatorname{com}(0,469)$; período $(t+3)$ com $(0,800)$ e período $(t+4)$ com $(0,839)$. Esse aumento médio é estatisticamente diferente, confirmado pelo Teste $t$ de student. Acredita-se que a evolução do desempenho pode estar atrelada ao evento das fusões e aquisições, que consiste em proporcionar maior segurança ao investidor que apostou em adquirir ações de empresas que passaram por fusões e aquisições. E, ainda, percebe-se nos cinco anos analisados que diversas companhias tiveram modificações positivas e negativas em suas posições no ranking, evidenciaram uma posição no ranking pré-fusão e aquisição que não se manteve estática nos quatro anos subsequentes ao período pós-fusões e aquisições.

Essas modificações no ranking podem ser explicadas pelo comportamento dos dados utilizados na base de cada filtro de Graham. Nesse recorte temporal dos períodos $(t-1)$ a $(t+$ 4) ocorreram alterações nos preços das ações, valor de mercado, taxa de dividendos utilizado nos filtros F1, F3, F4, F5. Também ocorreram modificações nos indicadores econômicofinanceiros das empresas, tais como: indicador contábil do capital de giro líquido, dívida total, valor contábil tangível, totais do ativo circulante e do passivo circulante usados nos filtros F6, F7 e F8.

Diversos trabalhos analisaram a aplicabilidade das premissas dos Filtros de Graham nos mercados de capitais brasileiro e internacionais (Lander, Orphanides \& Douvogiannis, 1997; Bildersee, Chen \& Zutshi, 1993; Arnott, Hsu, \& Moore, 2005; Passos, 2006; Passos \& Pinheiro, 2009; Artuso \& Chaves, 2010; Artuso, 2012; Silva, Silveira, Del Corso, \& Stadler, 2011; Woods, 2013; Kreuzberg et al. 2014; Ferreira \& Santos, 2014; Zin \& Tarso, 2016)

Diante dos resultados da Tabela 4, infere-se que as companhias que melhoraram seu ranking em relação às demais empresas estão preocupadas com o retorno do investimento dos acionistas. Assim, atuam no alinhamento de interesses entre gestores e acionistas. Já, com relação às empresas que caíram no ranking, possivelmente os seus gestores não conseguiram manter o desempenho superior ou superar o desempenho do grupo de empresas adquirentes. Assim, os problemas com os acionistas ficaram mais acirrados devido ao retorno menor ocorrido no período pós-fusão e aquisição.

Como procedimento complementar, realizou-se a substituição do desempenho da empresa pelos Filtros de Graham, via TOPSIS, pelo simples retorno das ações. Isso representa a retirada de indicadores econômicos e financeiros da avaliação do desempenho. Entretanto, o retorno das ações é uma métrica frequentemente utilizada nos estudos sobre performance empresarial.

Para isso, é apresentado inicialmente o desempenho das quarenta e duas companhias, calculado pelo retorno das ações nos períodos $(t-1),(t+1),(t+2),(t+3)$ e $(t+4)$, conforme Tabela 5. O cálculo do retorno das ações foi obtido com a divisão do preço da ação do ano de análise com o preço da ação do ano anterior, sempre utilizada a cotação das ações do último dia de pregão do ano. 
Tabela 5

Desempenho das companhias pelo retorno das ações

\begin{tabular}{|c|c|c|c|c|c|}
\hline NOMES DAS COMPANHIAS & $t-1$ & $t+1$ & $t+2$ & $t+3$ & $t+4$ \\
\hline ANDRADE GUTIERREZ CONCESSOES S.A. & 0,356 & 0,014 & 0,463 & 0,121 & 0,009 \\
\hline ALL AMERICA LATINA LOGISTICA S.A. & 0,374 & 0,082 & $-0,534$ & 0,938 & $-0,516$ \\
\hline ARTERIS S.A. & 0,356 & $-0,334$ & $-0,434$ & 1,777 & 0,791 \\
\hline BRASKEM S.A. & 1,537 & $-0,348$ & 0,045 & 0,641 & $-0,135$ \\
\hline BRF S.A. & $-0,317$ & 0,219 & 0,364 & 0,163 & 0,184 \\
\hline BROOKFIELD INCORPORAÇÕES S.A. & $-0,387$ & 2,342 & 0,125 & $-0,410$ & $-0,229$ \\
\hline CCR S.A. & 0,779 & 0,084 & 0,646 & $-0,048$ & $-0,093$ \\
\hline CIA ENERGETICA DE MINAS GERAIS - CEMIG & 0,049 & 0,023 & 0,372 & 0,031 & $-0,002$ \\
\hline COSAN S.A. INDÚSTRIA E COMERCIO & $-0,528$ & 1,278 & 0,100 & $-0,001$ & 0,578 \\
\hline CPFL ENERGIA S.A. & 0,160 & $-0,034$ & 0,266 & 0,257 & 0,340 \\
\hline DIAGNOSTICOS DA AMERICA S.A. & 1,555 & $-0,307$ & $-0,147$ & 0,110 & $-0,229$ \\
\hline DURATEX S.A. & $-0,675$ & 0,120 & $-0,384$ & 0,712 & $-0,004$ \\
\hline ECORODOVIAS INFRAESTRUTURA E LOGÍSTICA S.A. & 0,356 & 0,134 & 0,266 & $-0,101$ & $-0,191$ \\
\hline FIBRIA CELULOSE S.A. & 0,356 & $-0,322$ & $-0,464$ & 0,627 & 0,225 \\
\hline FLEURY S.A. & 0,356 & $-0,189$ & 0,088 & $-0,179$ & $-0,039$ \\
\hline GAFISA S.A. & 0,356 & $-0,682$ & 1,721 & $-0,139$ & $-0,649$ \\
\hline GENERAL SHOPPING BRASIL S.A. & 0,356 & $-0,869$ & 2,767 & 0,531 & $-0,133$ \\
\hline METALURGICA GERDAU S.A. & 0,682 & 0,767 & $-0,217$ & $-0,313$ & 0,302 \\
\hline GOL LINHAS AEREAS INTELIGENTES S.A. & $-0,026$ & $-0,772$ & 1,632 & $-0,006$ & $-0,500$ \\
\hline HYPERMARCAS S.A. & 0,356 & 2,003 & 0,127 & $-0,621$ & 0,955 \\
\hline INVESTIMENTOS E PARTICIP. EM INFRA S.A. - INVEPAR & 0,356 & 0,014 & 0,463 & 0,121 & 0,009 \\
\hline JBS S.A. & $-0,177$ & $-0,228$ & $-0,152$ & $-0,013$ & 0,476 \\
\hline LIGHT S.A. & 0,336 & 0,248 & $-0,150$ & 0,040 & $-0,153$ \\
\hline LUPATECH S.A. & 0,881 & 0,160 & $-0,290$ & $-0,769$ & $-0,560$ \\
\hline MARFRIG GLOBAL FOODS S.A. & $-0,508$ & $-0,187$ & $-0,445$ & $-0,007$ & $-0,528$ \\
\hline OI S.A. & 0,776 & 0,228 & $-0,246$ & $-0,075$ & 0,152 \\
\hline CIA BRASILEIRA DE DISTRIBUICAO & $-0,085$ & 0,077 & $-0,022$ & 0,363 & 0,171 \\
\hline PDG REALTY S.A. EMPREEND E PARTICIPACOES & 0,356 & $-0,547$ & 2,112 & 0,187 & $-0,409$ \\
\hline PETROLEO BRASILEIRO S.A. PETROBRAS & 0,409 & $-0,461$ & 0,659 & $-0,230$ & $-0,183$ \\
\hline RENAR MACAS S.A. & 0,068 & $-0,353$ & $-0,572$ & $-0,444$ & 0,467 \\
\hline SANTOS BRASIL PARTICIPACOES S.A. & 0,356 & $-0,754$ & 1,734 & 0,361 & 0,135 \\
\hline SCHULZ S.A. & $-0,447$ & 0,807 & 0,129 & $-0,173$ & 0,332 \\
\hline CIA SIDERURGICA NACIONAL & 0,447 & $-0,432$ & 1,079 & $-0,016$ & $-0,407$ \\
\hline TRANSMISSORA ALIANÇA DE ENERGIA ELÉTRICA S.A. & 0,868 & 0,567 & 0,939 & $-0,073$ & 0,203 \\
\hline TRACTEBEL ENERGIA S.A. & 0,299 & $-0,050$ & 0,209 & 0,322 & 0,162 \\
\hline CTEEP - CIA TRANSMISSÃO ENERGIA ELÉTRICA PAULISTA & 0,486 & 0,350 & 0,181 & 0,180 & $-0,397$ \\
\hline TPI - TRIUNFO PARTICIP. E INVEST. S.A. & 0,356 & $-0,855$ & 4,713 & 0,759 & $-0,017$ \\
\hline ULTRAPAR PARTICIPACOES S.A. & 0,356 & 0,005 & 0,463 & 0,121 & 1,778 \\
\hline VANGUARDA AGRO S.A. & 1,504 & $-0,680$ & 0,357 & $-0,070$ & $-0,685$ \\
\hline VIA VAREJO S.A. & 0,356 & 0,014 & 0,463 & 0,121 & 0,009 \\
\hline VULCABRAS/AZALEIA S.A. & 1,077 & $-0,065$ & 0,519 & 0,069 & $-0,723$ \\
\hline WEG S.A. & 0,828 & $-0,491$ & 0,519 & 0,220 & $-0,113$ \\
\hline MÉDIA & 0,356 & 0,014 & 0,463 & 0,121 & 0,009 \\
\hline
\end{tabular}

Nota. Fonte: Dados da pesquisa.

$\mathrm{Na}$ Tabela 5 são expostos os retornos individuais das quarenta e duas companhias nos períodos pré e pós-fusões e aquisições, juntamente com as médias de cada ano. Pelas médias anuais, verifica-se que no período pré-fusões e aquisições o retorno médio ficou em $(0,356)$. No período $(t+1)$ nota-se que o retorno caiu significativamente para $(0,014)$. Já no período $(t+2)$ ocorreu um retorno de $(0,463)$, que é expressivo e superior ao período $(t-1)$. No período $(t+3)$ o retorno das ações ficou em $(0,121)$ e, por fim, no período $(t+4)$ ficou em $(0,009)$. 
Foi aplicado o Teste $t$ Student de diferença de média entre os períodos $(t-1)$ em relação aos períodos $(t+1)$, $(t+2),(t+3)$ e $(t+4)$ e constatou-se que as médias são estatisticamente diferentes, exceto para a comparação entre os períodos $(t-1)$ e $(t+2)$.

Baseado nas médias, verifica-se que no período anterior ao evento os preços das ações demonstravam crescimento, talvez explicado pela boa reputação da empresa no mercado de capitais ou pela pré-visualização de uma reestruturação societária pelos investidores, que buscam maior retorno com as novas companhias formadas.

No período pós-fusões e aquisições, percebe-se que o retorno das ações foi positivo entre os quatro anos de análise. O maior índice foi identificado no segundo período após o evento. Como não houve média negativa, afirma-se que o preço médio das ações somente cresceu ou se manteve nos quatro anos da análise. A explicação possível para o retorno das ações talvez tivesse sido o desempenho econômico-financeiro crescente após a reestruturação societária. Os resultados da Tabela 5 corroboram os dados da Tabela 4 indicando também resultados crescentes de desempenho das companhias pós-fusões e aquisições.

\section{CONCLUSÃO}

Este estudo objetivou verificar o desempenho das companhias que passaram por fusões e aquisições por meio da mensuração dos Filtros de Graham. Foram identificadas 42 eventos de fusões e aquisições, aos quais foram aplicados os Filtros de Graham nos quatro anos posteriores, com o auxílio do método TOPSIS.

Como resultados tem-se que a avaliação de desempenho pelos Filtros de Graham produz especificamente a mensuração do desempenho econômico, financeiro e bursátil, esse último também denominado de mercado. Pela aplicação dos Filtros de Graham o desempenho econômico e financeiro é fundamentado pelo lucro líquido elevado da empresa, pela redução do endividamento e aumento das disponibilidades proporcionado pela elevação do ativo circulante em relação ao passivo circulante. Com esses indicadores, que também são contábeis, tem-se o diferencial da aplicação dessa metodologia, pois se avalia as empresas pós-fusões e aquisições por sua saúde financeira.

A aplicação dos Filtros de Graham também proporcionou a avaliação por meio do desempenho bursátil. Esta avaliação considera preço das ações e taxa de dividendo pago. Diferente dos demais estudos observados até o presente momento, essa técnica considerou em suas fórmulas a taxa de dividendo pago, que, por sua vez, estaria indicando relevante fluxo de caixa após as fusões e aquisições.

Pela avaliação de desempenho por meio dos Filtros de Graham, transformados em ranking pelo TOPSIS, constatou-se que houve um crescimento estatisticamente distinto ao longo dos quatro anos após as fusões e aquisições. Justifica-se que os sete Filtros de Graham via TOPSIS compõem uma forma de avaliação criteriosa do desempenho da empresa. Promete a segurança do principal e o retorno adequado para o investimento realizado. A análise criteriosa é necessária, pois quando um investidor está adquirindo uma ação da empresa que passou por uma fusão e aquisição, ele está tornando-se sócio daquele empreendimento. É necessário conhecer melhor suas operações, o seu desempenho e avaliar adequadamente seus ativos.

Analisando os resultados encontrados, conclui-se que os gestores das empresas pesquisadas prezaram por um conjunto de índices composto pelos Filtros de Graham após as fusões e aquisições para que as empresas tivessem bons indicadores de mercado e adequada saúde financeira, essa última composta pela boa estrutura de capital e baixo risco de insolvência. Dessa forma, pagaram bons dividendos aos seus acionistas e estruturaram bem financeiramente a companhia, ou seja, tomaram boas decisões financeiras que foram identificadas pelos Filtros de Graham. Assim, infere-se que o relevante desempenho das companhias, mensurado pelos Filtros de Graham, indica que os interesses dos acionistas e gestores estão alinhados e contribuem para a melhor governança corporativa da empresa.

Por conseguinte, recomenda-se, como sugestão para novas pesquisas, análises de desempenho aplicando-se diferentes metodologias de avaliação das empresas, tais como: retorno anormal das ações, $Q$ de Tobin, índices de sustentabilidade, entre outras. Recomenda- 
se, também, realizar a avaliação de desempenho pelos Filtros de Graham com as empresas que realizam ofertas públicas de ações.

\section{REFERÊNCIAS}

Arnott, R. D., Hsu, J., \& Moore, P. (2005). Fundamental indexation. Financial Analysts Journal, 61(2), 83-99.

Artuso, A. R. (2012). Análise multivariada e filtros de graham: reconhecimento de padrões aplicado ao mercado acionário brasileiro (Doctoral dissertation, Universidade Federal do Paraná).

Artuso, A. R., \& Chaves, A., Neto (2010). O uso de quartis para a aplicação dos filtros de Graham na Bovespa (1998-2009). Revista Contabilidade \& Finanças, 21(52).

Benitez, J. M., Martin, J. C., \& Roman, C. (2007). Using fuzzy number for measuring quality of service in the hotel industry. Tourism Management, 28(2), 544-555.

Berk, D. \& Demarzo, P. (2009). Corporate Finance (2a ed.). Boston: Pearson.

Bildersee, J. S., Chen, J. J., \& Zutshi, A. (1993). The performance of Japanese common stocks in relation to their net current asset values. Japan and the World Economy, 5(3), 197-215.

Bogle, J. C. (2008). A question so important that it should be hard to think about anything else. Journal of Portfolio Management, 34(2), 95.

Bogle, J. C. (2009). The Fiduciary Principle: No Man Can Serve Two Masters. Journal of Portfolio Management, 36(1), 15-25.

Bulgurcu, B. K. (2012). Application of TOPSIS Technique for financial performance evaluation of technology firms in Istanbul Stock Exchange Market. Procedia - Social and Behavioral Sciences, 62(24), 1033-1040.

Calandro, J., Jr. (2009). Lessons for strategists in Graham \& Dodd's security analysis. Strategy \& Leadership, 37(2), 45-49.

Camargos, M. A., \& Barbosa, F. V. (2003). Fusões e aquisições e takeovers: um levantamento teórico dos motivos, hipóteses testáveis e evidências empíricas. Cadernos de pesquisas em administração USP, 10(2), 17-38.

Cheung, J. H. B. (2010). Does Mr. Market Suffer from Bipolar Disorder? Journal of Behavioral Finance, 11(4), 224-238.

Damodaran, A. (2006). Filosofias de Investimento. Rio de Janeiro: Qualitymark.

Ferreira, R. L. S., \& Santos, D. F. L. (2014). Análise do desempenho dos filtros de Graham e o modelo de Elton-Gruber para o Brasil entre 2008 a 2012. Revista Brasileira de Administração Científica, 5(3), 183-202.

Gil, A. C. (2006). Métodos e técnicas de pesquisa social (5a ed.). São Paulo: Atlas.

Gitman, L. J. (1997). Princípios de administração financeira. Harbra.

Graham, B. (2007). O Investidor inteligente. Rio de Janeiro: Nova Fronteira.

Graham, B., \& Dodd, D. L. (1951). Security analisys (3a ed.). New York: McGraw-Hill.

Gray, C. S. (2012) Airpower for Strategic Effect. Alabama: Maxwell AFB.

Hair, J. F., Jr., Babin, B., Money, A. H., \& Samouel, P. (2005) Fundamentos de métodos de pesquisa em administração. Porto Alegre: Bookman.

Hwang, C. L., \& Yoon, K. (1981). Multiple attributes decision making methods and applications. Berlin: Springer.

Kerlinger, F. N. (1980). Metodologia da pesquisa em ciências sociais: um tratamento conceitual. São Paulo: EPU. 
Kloechner, G. O. (1994). Fusões e aquisições: motivos e evidências empíricas. Revista de Administração, 29(1), 42-58.

KPMG Cutting Through Complexity. (2013). Pesquisa de Fusões e Aquisições 2013 - 4ำ trimestre: Espelho das transações realizadas no Brasil. Recuperado de https://www.kpmg.com/BR/PT/Estudos_Analises/artigosepublicacoes/Documents/Fusoes \%20e\%20Aquisicoes/2013/FA-4-trimestre-2013.pdf

Kreuzberg, F., Beck, F., Gollo, V. \& Rosa, F. S. (2014). Avaliação das carteiras de investimento das empresas listadas nos níveis de governança corporativa da BM\&FBovespa: Uma aplicação dos filtros de Graham. Race: Revista de Administração, Contabilidade e Economia, 13(3), 955-978.

Lander, J., Orphanides, A. \& Douvogiannis, M. (1997). Earnings forecasts and the predictability of stock returns: evidence from trading the S\&P. The Journal of Portfolio Management, 23, 4, 24-35.

Lowe, J. (1997). Value investing made easy: Benjamin Graham's classic investment. New York: McGraw-Hill.

Marion, P. J., Filho, \& Vieira, G. M. (2010). Fusões e aquisições (F\&A) de empresas no Brasil (1990-2006). Revista de Administração da UFSM, 3(1), 109-130.

Martins, G. A. \& Theóphilo, C. R. (2009). Metodologia da investigação científica para ciências sociais aplicadas. São Paulo: Atlas.

Mellagi, A., Filho, \& Ishikawa, S. (2003). Mercado financeiro e de capitais (2a ed.). São Paulo: Atlas.

Nardi, R. Y. S. (2012). Criação de valor em fusões e aquisições: a influência do sentimento de mercado (Doctoral dissertation, Universidade de São Paulo).

Oppenheimer, H. R. (1984). A test of Ben Graham's stock selection criteria. Financial Analyst Journal, 40(5), 68-74.

Passos, V. C. S. (2006). Estratégias de investimento em Bolsa de Valores: uma pesquisa exploratória da visão fundamentalista de Benjamin Graham. (Doctoral dissertation, Faculdade de Ciências Humanas de Pedro Leopoldo, Pedro Leopoldo).

Passos, V. D. C. S., \& Pinheiro, J. L. (2010). Estratégias de investimento em bolsa de valores: uma pesquisa exploratória da visão fundamentalista de Benjamin Graham. Revista Gestão \& Tecnologia, 9(1), 1-16.

Shleifer, A., \& Vishny, R. (1989). Management entrenchment: the case of manager-specific investments. Journal of Financial Economics, 25(3), 123-139.

Silva, D. H. F., Gallo, M. F., Pereira, C. A., \& Lima, E. M. (2004). As operações de fusão, incorporação e cisão e o planejamento tributário. Anais Congresso USP Controladoria e Contabilidade, São Paulo, 4. Recuperado de http://www.eac.fea.usp.br/

Silva, W. V., Silveira, S. A. A. de, Del Corso, J. M., \& Stadler, H. (2011). A influência da adesão às práticas de governança corporativa no risco das ações de empresas de capital aberto. Revista Universo Contábil, 7(4).

Singh, H., \& Montgomery, C. A. (1987). Corporate acquisitions strategies and economic performance. Strategic Management Journal, 8(4), 377-386.

Wang, C., \& Xie, F. (2009) Corporate governance transfer and synergistic gains from mergers and acquisitions. Review of Financial Studies, 22(2), 829-858.

Weston, J. F. (1994). The payoff in mergers and acquisitions. In M. Rock, R. H. Rock \& M. Stroka (editors). The mergers and acquisitions handbook (2a ed.). New York: McGrawHill.

Woods, J. E. (2013). On Keynes as an investor. Cambridge Journal of Economics, 61. 
Zargham, M. R., \& Hu, L. (1996). Assigning weitghs to rules of an expert system based on fuzzy logic. In T. Tanaka, S. Ohsuga \& M. Ali (Orgs.) Industrial and engineering applications of artificial inteligence and expert systems (pp. 189-193). Fukuoka: Gordon and Breach Publishers.

Zin, R. A. \& Tarso, E. (2016). Como o pequeno investidor pode usar as Teorias de Graham e Markowitz. REAVI-Revista Eletrônica do Alto Vale do Itajaí, 4(6), 28-41. 